\title{
A PRIMIGRAVIDA WITH TAKAYASU AORTOARTERITIS WITH BILATERAL RENAL ARTERY STENOSIS DELIVERED VAGINALLY: A RARE INTERESTING CASE
}

\author{
Swati Gawai ${ }^{1}$, Pradnya Changede ${ }^{2}$, Niranjan Chavan³ ${ }^{3}$ Y. S. Nandanwar ${ }^{4}$
}

\section{HOW TO CITE THIS ARTICLE:}

Swati Gawai, Pradnya Changede Niranjan Chavan, Y. S. Nandanwar. "A Primigravida with Takayasu Aortoarteritis with Bilateral Renal Artery Stenosis Delivered Vaginally: A Rare Interesting Case". Journal of Evolution of Medical and Dental Sciences 2015; Vol. 4, Issue 56, July 13; Page: 9852-9854,

DOI: $10.14260 /$ jemds/2015/1424

\begin{abstract}
We are presenting a case of 24 years, primigravida, Takayasu aortoarterities with bilateral renal artery stenosis diagnosed during pregnancy and delivered vaginally in a tertiary care institute.
\end{abstract}

KEYWORDS: Takayasu aortoarterities, Hypertension, Intra uterine growth retardation, Renal artery stenosis, Vaginal delivery.

CASE REPORT: 24 years, Primigravida, Takayasu aortoarterities with bilateral renal artery stenosis married since 1 year, 38 weeks of gestation had come with, c/o leaking per vaginum since 1 hour (11am on 3/12/14), Pain in abdomen since 1 hour. Patient was known case of Takayasu aortoarterities with bilateral renal artery stenosis since 3 months, on regular medication (T. Aldomet 500 QID, T. Nicardia 10mg QID, T. Azoran 50mg BD, T. Prednisolone 1mg/Kg/day.)Patient found to be hypertensive during her $1^{\text {st }}$ visit $\approx 14$ wks of gestation and was started on Tab Aldomet $250 \mathrm{mg}$ QID. At $21^{\text {st }}$ weeks of gestation patient was diagnosed as a case of Takayasu Aortoarterities with bilateral renal artery stenosis and started on T. Aldomet 500 QID, T. Nicardia $10 \mathrm{mg}$ QID, T.Azoran $50 \mathrm{mg}$ BD, T. Prednisolone $1 \mathrm{mg} / \mathrm{Kg} /$ day.2D Echo-s/o thickening of descending and abdominal aorta with maximum thickness at diaphragmatic level. Renal Doppler-s/o bilateral renal artery stenosis. Patient had regular ANC follow up. Patient was induced with cerviprime gel, augmentation done with oxytocin. $2^{\text {nd }}$ stage of labor was cut short by outlet force application. Post-delivery patient was stable and post delivery period was uneventful.

INTRODUCTION: Takayasu Arteritis was first described in 1908 by two Japanese ophthalmologists, Takayasu and Onishi, who observed retinopathy in the absence of peripheral pulses ${ }^{1}$. Although more common in Oriental women it is seen worldwide. The cause is unknown, but it seems to be related to autoimmunity, sex hormones(More common in young females), and genetics(Demonstrated by the predisposition of the human leukocyte antigen - HLA BW52). ${ }^{2}$ Four types of Takayasu Arteritis can be identified: Type I(Disease involving the aortic arch and its branches), type II (Lesions restricted to descending thoracic aorta and abdominal aorta), type III (Patients have characteristics of types I and II), and type IV (Involvement of the pulmonary artery).

The disease can also be classified into stages according to the presence of major complications such as hypertension, retinopathy, aneurysms, and aortic insufficiency. Stage I, no complications are observed; stage IIa, patients have only one of these complications; and stage IIb, patients have only one of these complications, but the severe form; stage III, when more than one complication is present. The patient presented here was in stage II, but during pregnancy her hypertension was compensated and her aneurysm had been corrected. 


\section{CASE REPORT}

Takayasu's arteritis (TA) is a primary arteritis of unknown cause, which occurs in the women of the childbearing age. ${ }^{3}$ the mean age of presentation of TA is usually in the second and third decade of life with a greater prevalence in Asian women, it occurs sporadically throughout the world. It is more common in women than men (8:1), and the peak incidence is in the second and third decades.2,3

The disease preferentially involves the elastic arteries including the aorta and its major branches. Typical histopathological changes consist of disruption of the elastic fibers of the vessel wall, inflammatory cell infiltration with occasional granulomatous reaction, fibrotic thickening of the adventitia and intimal thickening. Maternal complications are superimposed pre-eclampsia (60\%), congestive cardiac failure (5\%), cerebral haemorrhage (5\%) progressive renal impairment and fetal complications include growth restriction. ${ }^{4}$

All women should receive regular growth scans. Uterine artery Doppler ultrasound scans, performed at 20 and 24 weeks of gestation, provide a predictor for uteroplacental function and help to identify women with the highest risk pregnancies, who should be monitored more intensely thereafter. ${ }^{4}$ In spite of the limitations of clinical, ultrasound and umbilical artery doppler assessment, the knowledge of reduction in growth helps to predict the failing placenta and thereby allows the planning of early delivery.

Apart from hypertension, there were no major obstetric problems and no maternal deaths directly related to pregnancy. Pregnancy can continue till term and induction of labour is considered in the presence of superimposed pre eclampsia or hypertension. Elective Caesarean at term is indicated for severe disease (Retinopathy, arterial aneurysms, and aortic regurgitation). Hypertension in the second stage of labour is a risk factor for cerebral haemorrhage; shortening this stage by use of low forceps delivery or vacuum extraction appears to be a reasonable solution.

DISCUSSION: Diagnosis is based on signs and symptoms, inflammatory markers, and arteriography demonstrating aortic stenosis and of its branches. However, the gold-standard for diagnosis is the biopsy of the vessel. Pregnancy does not interfere on disease progression, although hypertensive complications such as preeclampsia and exacerbation of chronic hypertension, and fetal complications such a restriction of intrauterine growth, abortion, and fetal death have been reported in $60 \%$ to $90 \%$ of the cases. The high incidence of restricted uterine growth seems to be related to uncontrolled hypertension and aorta and iliac arteries involvement. Arterial ultrasound Doppler, which quantifies the flow in the uterine arteries, is another way of evaluating fetal well-being and growth in patients with TA. Few patients are asymptomatic and more than $60 \%$ have some kind of complication. Hypertension, caused by reduction in elasticity and narrowing of the aorta and its branches, besides abnormalities in the function of the aortic and carotid baroreceptors function, is the most common. ${ }^{5}$

Occlusive and steno tic lesions might require revascularization by percutaneous angioplasty, use of endoprosthesis, or surgical correction. Treatment of TA involves the use of corticosteroids, the first line treatment for inflammatory activity as well as immunosuppresses including methotrexate and azathioprine. Chronic use of corticosteroids could lead to suppression of adrenal gland activity with inadequate release of endogenous corticosteroids in moments of stress, such as surgeries. In our case, patient was diagnosed of the disease during pregnancy at $14^{\text {th }}$ week of gestation and was started on medications. She was asymptomatic and had regular ANC visits. She delivered vaginally under vigilance with no complications. 
CONCLUSION: Takayasu arteritis is rare disease and if diagnosed early complications during pregnancy, labor and post-delivery can be avoided if good ANC care and monitoring is available and delivery is planned in a tertiary care with all the facilities. Also patients can be delivered vaginally if there is no obstetric indication with good fetal and maternal outcome.

\section{REFERENCES:}

1. Plínio da Cunha Leal, Fernanda Fabrízia Martins Silveira, Eduardo Jun Sadatsune, Jefferson Clivatti, Américo Masafuni Yamashita CLINICAL INFORMATION Takayasus's Arteritis in Pregnancy. Case Report and Literature Review.

2. Vitthala S, Misra P. Original Article Takayasu's Arteritis \& Pregnancy: A Review.

3. Rupali N Sawant, Binti Bhatiyani, Pradip Gaikwad, Sara Azad. Successful Pregnancy in a Patient with Takayasu Arteritis: a case report. Int J Reprod Contracept Obstet Gynecol.2013; 2(3): Takayasu Arteritis in Pregnancy.

4. Luis M. Graça, Maria C. Cardoso Frederico S. Machado, Takayasu's arteritis and pregnancy: a case of deleterious association Accepted: November 28, 1986; EUROPEAN JOURNAL OF OBSTETRICS AND GYNAECOLOGY AND REPRODUCTIVE BIOLOGY.

5. Hauenstein E1, Frank H, Bauer JS, Schneider KT, Fischer T. J. Perinat Med. 2010; 38(1): 55-62. doi:10.1515/JPM.2009.120.Takayasu's arteritis in pregnancy: review of literature and discussion.

\section{AUTHORS:}

1. Swati Gawai

2. Pradnya Changede

3. Niranjan Chavan

4. Y.S. Nandanwar

\section{PARTICULARS OF CONTRIBUTORS:}

1. Registrar, Department of Obstetrics \& Gynaecology, LTMMC \& Sion Hospital, Mumbai.

2. Assistant Professor, Department of Obstetrics \& Gynaecology, LTMMC \& Sion Hospital, Mumbai.

3. Unit Head, Department of Obstetrics \& Gynaecology, LTMMC \& Sion Hospital, Mumbai.

FINANCIAL OR OTHER COMPETING INTERESTS: None
4. HOD, Department of Obstetrics \& Gynaecology, LTMMC \& Sion Hospital, Mumbai.

\section{NAME ADDRESS EMAIL ID OF THE CORRESPONDING AUTHOR: \\ Dr. Swati Gawai, Room No. 302, Old RMO, LTMMC \& Sion, Mumbai. \\ E-mail: gawai.swati@gmail.com}

Date of Submission: 29/06/2015.

Date of Peer Review: 30/06/2015.

Date of Acceptance: 07/07/2015.

Date of Publishing: 13/07/2015. 